\title{
Students, computers and learning: Where is the connection?
}

\author{
Chenglie Hu ${ }^{1}$
}

Published online: 17 November 2017

(C) Springer Science+Business Media, LLC, part of Springer Nature 2017

The report released by the Organization for Economic Cooperation and Development (OECD) in 2015, titled: Students, Computers and Learning: Making the Connection, has drawn considerable worldwide reaction on what appears a dismal reality: computers do not improve student results. Despite the limited data and sources it used, the report voiced the challenges many countries' school systems face in finding more effective ways for teachers to integrate information and communication technology (ICT) into teaching and learning in their classrooms to provide students with learning environments that support their learning needs of the twenty-first century. Our school systems have been investing in every way they can in use of ICT to improve education. However, have they invested effectively to ensure that teachers are at the forefront of designing and implementing ICT-integrated pedagogical methods in their classrooms? This Special Issue of the Journal intends to promote making the connection between use of ICT and evidence-based learning and practice. The articles you will be reading may not represent the state-of-the-art of ICT use in education today. Nevertheless, these articles reflect the efforts the educators around the world have made in pursuing effective use of ICT in their teaching practices, as well as in identifying the issues educators are still facing today in their pursuits. These articles also reflect our improved understanding about the pedagogical value of ICT, and particularly, the future of ICTintegrated education that still requires much exploration.

A prevailing way to make a connection between ICT and learning is to use educational software to facilitate learning and teaching about difficult concepts and skills. Use of educational software could reinforce knowledge acquisition and retention; and it is particularly effective for learning languages by non-native speakers. The article authored by Barley Mak et al. reports a study about the impact of a software program used for learning English as a second language (https://doi.org/10.1007/s10639-0179620-3).The study found that the software helped students improve their language

Chenglie $\mathrm{Hu}$

chu@carrollu.edu

1 Carroll University, Waukesha, WI, USA 
skills in areas where use of the software made significant difference compared to traditional ways of learning. However, when use of the software was marginally favorable, it did not result in better learning outcomes. The findings, drown from experiments on Chinese-speaking population, are mostly consistent with those in similar studies reported elsewhere in the world. In other words, good educational software likely makes a global impact across nations, and continues to be a focus of future ICT development.

Developing countries may face different challenges. Particularly, they face challenges of lacking infrastructural support for use of ICT in teaching and learning. The article authored by Olugbenga Adedayo et al. presents a case study in a developing country, which shows that a simple use of ICT in classroom may result in students outperforming those with traditional learning approaches, even those with blended methods (https://doi.org/10.1007/s10639-017-9598-x). The ICT use in the experiment was rudimentary, involving only reading digitally and lecturing with Power Point presentations. Given a particular course the research was based upon, the study might convey a simple message that ICTs would provide naturally effective ways for knowledge scan and initial memorization based on facts, which is an important step for knowledge elaboration, retention, and acquirement. In the context of a developing country however, making basic ICT applications widely accessible might be a vital step in literacy education, as well as in delivering the basic education to all citizens.

How might ICTs assist students who have learning disabilities with their learning needs? The answers likely depend upon the ways disabilities may affect learning. Although much of the ICT use by students with learning disabilities may be considered as providing needed accommodations, ICT has significantly changed the way learning takes place for such students despite their disabilities. ICTs enable physically impaired students to engage in learning electronically by avoiding their physical constraints. ICTs also allow cognitively challenged students to engage in learning in a variety of forms, which may significantly reduce the learning curve, leading to improved learning results. The article authored by Arthur Tatnall et al. provides two case studies that demonstrated interactions between students with learning disabilities and ICT facilities (https://doi.org/10.1007/s10639-017-96052). The study showed how ICTs may improve students' attitudes towards learning, and help them attain knowledge and skills, which in turn allow them to enter the workforce or continue with further study through a variety of pathways. On a slightly different note, would students with disabilities necessarily use more ICT in learning when they enrolled in distance-education or hybrid classes than do their counterparts who receive education in more traditional settings? In the article authored by Tali Heiman et al., the researchers suggested that the answer to the question is most likely affirmative based on their findings (https://doi.org/10.1007 /s10639-017-9623-0). Furthermore, they found that instructors who were teaching distance-education classes used more ICTs than they would otherwise in classes that are more traditional. Despite the research conducted in two countries, the researchers observed that the findings appeared insensitive to the local culture and education system. However, the researchers cautioned that having access to ICTs by students with learning disabilities does not necessarily mean they would benefit fully from the use in their knowledge acquisition. Such students would need handholding before they are able to take full advantage of using the technologies 
in meeting their learning needs beyond the use for merely accommodating their disabilities.

How might pedagogy of a specific kind impact ICT-integrated learning? "Flipping classroom" is often an effective way of promoting constructivist-based learning. However, what might happen if such a learning experience involves learning to use a piece of software of ICT, and at the same time, using ICT for class operation? The article authored by Kathleen Molnar presents a case study about students learning to use a productivity software program in distinctive class environments - web-enhanced, face-to-face, or hybrid, with classes "flipped" however (https://doi.org/10.1007 /s10639-016-9568-8). As the study shows, there is a significant difference in student perception about the flipped course itself among classes of different operational modes. However, this, as the author found, may depend upon the level of technology integration and instructor's prior experience in online teaching, rather than the (flipped classroom) approach. In addition, students who were required to work in groups on a weekly basis had more positive responses toward their flipped-classroom experience than those who were, as they felt that the flipped classes improved their soft skills. Nevertheless, the students in the flipped classes and those in the more traditional learning settings attained comparable learning outcomes in the experiment, measured by the grades. The author concluded that teaching software skills could be more effective with at least some direct (face-to-face) instruction than with just simulation software that students would use on their own. In recent years, game-based learning, that is, learning that feels like playing in a game, is another widely used pedagogical strategy despite its controversy. The hypothesis was that gamification of learning may better motivate students. This strategy is based upon the assumption that many of today's students, growing up in a digital world, may be more interested in learning experiences that could be associated, in some way, with games. The article authored by Amna Khan et al. reports an investigation into such a scenario, particularly student's engagement in a gamification-learning environment (https://doi.org/10.1007/s10639017-9622-1). The authors found that gamification - digital or not - does improve student's engagement in learning, but the level of engagement might depend upon the type of game designed, in which students who were more interested in such games tended to be engaged more in learning. Such a phenomenon, as the researchers observed, might also be gender-dependent. However, engagement in learning does not necessarily lead to better learning results. The researchers found that despite more engagement by students, gamification in their experiment did not actually bring significant improvement in learning outcomes, especially for male students who showed less interest in the type of game teachers designed. Nevertheless, the researchers still held the hope that game-based learning might provide an effective way to engage youngsters more in learning, particularly those from economically disadvantaged families. As a takeaway from these studies, whether, how, and when an ICT integration would work well with a specific pedagogical approach might depend upon students' pre-existing knowledge in terms of whether they would be able to adapt to the approach quickly and more easily. It could also depend upon instructor' prior experience, which might be important in the design of an effective integration. However, more importantly, an effective integration of ICT into a pedagogical strategy would need to be deliberate, thoughtfully designed, and iteratively tested for continual improvement of the practice. 
The promises of ICT use in improving educational practices and results are often more speculated than delivered. Although there can be a variety of reasons that attempts of ICT integration fall short, lack of reflective loops for improvement can often be associated with failures. The article authored by Eric Sanchez et al. describes a model for process (of ICT integration) improvement (https://doi.org/10.1007/s10639-0179624-z). As the authors argued, to ensure success, ICT integrations into teaching and learning need to be research-oriented, and researches must involve practitioners - the teachers. Furthermore, the design of such a research defines a protocol of communication between researchers and practitioners in a fashion similar to a roleplaying game. This process of communication represents a collaboration that advances shared practices (such as an innovative use of ICT in class instruction) and the reasoning behind the practices. There are likely gaps between practitioners and researchers about their understandings underpinning the practices and beliefs. Thus, people involved may need a broker to mediate the differences, convey the knowledge, and facilitate reaching an agreement between researchers and practitioners. Promoting a collaborative effort in seeking effective ICT integrations in learning, this model of design-based research presents a way of ensuring not only the quality of an ICT integration, but more importantly also its sustainability. Meanwhile, learning theories often perceive reflective learning to be fundamental to effective learning. Along this line, Krishnashree Achuthan et al. presented a case study about the impact of virtual laboratories on learning (https://doi.org/10.1007/s10639-017-9626-x). They found that students who used virtual laboratories for training before they used a physical laboratory, and again for post-lab exercises demonstrated a significant improvement in learning, compared to learning without virtual laboratories. The researchers argued that ICTs, such as virtual laboratories, could effectively support reflective learning, expand students' learning capacities, and boost knowledge retention. From a different perspective, the article authored by Antonia Scholkmann et al. looked at another way of ensuring quality of an ICT integration through the lens of problem-based learning, which is also a practice based upon constructivist theory of learning (https://doi. org/10.1007/s10639-017-9629-7). The study shows that students gained competence by taking advantages of such a learning approach only if they actively participate in designed learning activities. In many ways, ICT has revolutionized the way knowledge is presented, conveyed, and received. However, the challenge of ICT integration in learning is the use of the technologies to facilitate knowledge comprehension, retention, and application. To meet the challenge, these studies suggested a collaborative effort in ICT integration in education that goes into the territory of deep learning to engage learners in knowledge acquisition and application through critical and analytical thinking, thus achieving a higher level of learning outcomes.

To ensure effective ICT integrations, teachers must be at the center of delivering innovative use of ICT in their classrooms. Yet, teachers cannot be technologically competent without a proper training. Thus, investing in teachers' professional development is essential to driving meaningful experiments of ICT integration in teachers' classroom practices. However, prior to such an investment, it is equally important to know the teachers' technological needs. Two articles in this Special Issue are related to this theme. The article authored by Ann Zeta George et al. looks into thirty-three teacher-designed and technology-based tasks in eight subject areas by measuring their effectiveness of ICT use and their potential to involve students in constructivist-based 
learning (https://doi.org/10.1007/s10639-017-9609-y). For instance, a simulation of chemical reactions to help students balance chemical equations was rated high on technology use to enhance leaning and on likelihood of the task that promotes constructivism, whereas checking a paper-based test against a memo on a learning management system in order to make corrections was rated low on both aforementioned aspects. In a complimentary way, the article authored by Anders Olofsson et al. reports a study on what teachers want to know about ICT use in teaching and learning at a secondary school level (https://doi.org/10.1007/s10639-017-9590-5). Eighty-four secondary school teachers participated in this longitudinal study, in which they expressed opinions of themselves, and in behalf of their colleagues and their students. The content analysis revealed six areas of needs: technological aspects of teaching innovation, appropriate ICT integration in class instruction, effective use of a learning management system, concerns about security and plagiarism, learning from best practices, and collaborative effort in instructional design and development. Studies of these kinds can inform new research designs in multiple ways such as surveying students in light of teachers' perspectives, designing and implementing ICT intervention trials in teachers' own classrooms, or evaluating effectiveness of workshops of disseminating successful practices. It is worth mentioning that both articles discussed the findings in relation to a conceptual model that describes the relations among knowledge about technology, knowledge about pedagogy, and content knowledge (TPACK model). With their own education, teachers know how to apply appropriate pedagogy to teaching the content. However, effective integration of ICT into their teaching requires new knowledge to ensure appropriate use of ICT, and effective evaluation of the impact of the technology use on student results. If we could define "kernel knowledge" to be the intersection of these three kinds of knowledge, then this "kernel knowledge" would be required in order for teachers to be innovative in use of ICT, for researchers to ground their studies on practices, and for our schools' administrators to address effectively teachers' needs for professional development.

Finally, a review article authored by Martie Sanders et al. summarizes lessons learned from the past practices of ICT use in teaching and learning (https://doi. org/10.1007/s10639-017-9604-3). These lessons included overstated benefits of ICT use, inappropriate use of ICT, invalid claims about assumed ICT benefits, and unanticipated side and often-negative effects associated with use of educational software. The authors suggested that effective use of ICT in education needs careful planning, continued investment, and more importantly professional development for teachers. Given the ever-changing landscape of educational technology, the authors suggested that setting attainable goals linked to specific education contexts might be vital to successful attempts of ICT integrations.

In closing, ICTs have enabled new ways education is delivered, created new venues where learning takes place, and improved our ability to deliver more effective pedagogies to improve student results. Research endeavors have shown that students can use technologies to reach and acquire information in unlimited ways for exploration, for personalized learning, for instant feedback on learning with intelligent systems, and for creativity with open-ended inquiries. There is also overwhelming evidence in the literature about the use of technologies for collaborative learning through social networks, for bridging previously disconnected learning channels with multimedia, and for extending the range of time and place for learning. All of these point to a 
positive linkage between use of ICT in learning and attainment of expected results. However, this linkage is conditional, and requires in fact systematic planning, design, and experimentation to establish. For instance, use of ICT may get students to practice more in those knowledge areas where practice used to be difficult; but teachers need to identify such areas, and motivate and engage students in designed learning activities to achieve the assumed benefits. Use of ICT allows knowledge to be presented in different forms; but these forms would make sense to students only if they are able to explore and understand the inter-connections of the forms to improve their understanding of the knowledge conveyed. ICT takes class discussion and collaborative learning to virtual environments; but it requires students to participate actively in discussion forums and designed collaboration activities to benefit from such learning platforms. ICT changes rapidly, which offers ever greater opportunities to support teaching and learning; but this rapid advancement of technology must be accompanied by a continued support for teachers to develop new technological and pedagogical skills in order for them to update their practices and more effectively evaluate what they have done in their classrooms.

Despite the progress that has been made in teaching and learning with integrated information and communication technology, many questions remain today about effective use of technologies. For instance, how would we manage the side effect of the technologies that may distract students from, or even negatively affect, the learning? Can students become dependent on ICTs when technologies outthink them in solving problems? What would be implications when technologies provide students with inaccurate feedback leading to incorrect interpretation of a learning process? However, there are also more intriguing questions to ask. Can students use ICT for cognitively deep learning, and how are we able to design such learning environments when ICTs are highly accessible? Is it possible to design pedagogies with meaningful blend of ICT to support effective learning with learners having diverse learning habits and abilities? Pedagogies we adopt are key, particularly to the design of pedagogical strategies that require deep, conceptual and higher-order thinking. Thus, to ensure our success, it is vitally important to advance our understanding of the connection among the conceptual frameworks of knowledge, pedagogical approaches, and the technologies we employ. We must understand not only what connections we can possibly make, but also, more importantly, how we can make them to supplement traditional teaching, amplify effective teaching, and create ICT-integrated teaching based upon inquiry and evidence. We have entered a new era of machine learning, which may support learning in new ways by analyzing learning data in order to deliver just-in-time contents, instructions, and practices. In the end however, the connections between students, computers and learning are only as promising as we make them. 